Anticonvulsants used by $860^{\star}$ obstetricians to treat pre-eclampsia and eclampsia

\begin{tabular}{lcc} 
& \multicolumn{2}{c}{ Anticonvulsant used to treat } \\
\cline { 2 - 3 } Anticonvulsant & Pre-eclampsia & Eclampsia \\
\hline None & 348 & \\
\hline Magnesium sulphate & 183 & 517 \\
\hline Only & 90 & 229 \\
\hline With diazepam & 26 & 215 \\
\hline With phenytoin & 27 & 14 \\
\hline With diazepam and phenytoin & 17 & 40 \\
\hline With other & 352 & 19 \\
\hline Diazepam & 113 & 573 \\
\hline Only & 90 & 162 \\
\hline With magnesium sulphate & 73 & 215 \\
\hline With phenytoin & 76 & 104 \\
\hline With other & 227 & 92 \\
\hline Phenytoin & 76 & 204 \\
\hline Only & 73 & 22 \\
\hline With diazepam & 26 & 104 \\
\hline With magnesium sulphate & 52 & 14 \\
\hline With other & 60 & 64 \\
\hline Chlormethiazole & 5 & 59 \\
\hline Only & 23 & 5 \\
\hline With diazepam & 32 & 24 \\
\hline With other & 3 & 30 \\
\hline Other & 3 & 1 \\
\hline Not answered & $160(15 \%)$ \\
\hline
\end{tabular}

${ }^{*} 1020$ respondents out of $1400(72.9 \%) ; 160(15.7 \%)$ were not in clinical practice and were therefore excluded.

Uncertainty about the role and choice of prophylactic anticonvulsant treatment for preeclampsia is reflected in the variation in clinical practice. For example, an increasing proportion of obstetricians never use prophylactic anticonvulsants
( $16 \%$ in $1991 v 23 \%$ in 1996). ${ }^{2}$ Among those who do there is no consensus on which agent to use or when prophylaxis is appropriate (data not shown). One aim of our survey was to assess the feasibility of conducting a multicentre, randomised, placebo controlled trial of magnesium sulphate versus placebo in women with pre-eclampsia. Over half of the respondents indicated their interest in collaborating in such a study compared with only $3 \%$ of respondents in the 1991 survey. ${ }^{2}$ This confirms the increased uncertainty about the role of anticonvulsants in women with pre-eclampsia.

We thank the respondents to our questionnaire.

Contributors: LD had the original idea and participated in the design and conduct of the study. AMG participated in the design and conduct of the study and was responsible for coordination. Both authors supervised the analysis and wrote the paper and will act as guarantors for the paper. Sarah Ayers provided programming support and Caroline Busby entered the data.

Funding: This study was funded by a grant from the Department for International Development; it does not take any responsibility for the contents of this article.

Conflict of interest: None.

Chamberlain GVP, Lewis PJ, De Swiet M, Bulpitt CJ. How obstetricians manage hypertension in pregnancy. BMJ 1978;276:626-9.

2 Hutton JD, James DK, Stirrat GM, Douglas KA, Redman CWG. Management of severe pre-eclampsia and eclampsia by UK consultants. $\mathrm{Br} \mathrm{J}$ Obstet Gynaecol 1992;99:554-6.

3 Eclampsia Trial Collaborative Group. Which anticonvulsant for women with eclampsia? Evidence from the collaborative eclampsia trial. Lancet 1995;345:1455-63.

4 Duley L, Gülmezoglu AM, Henderson-Smart DJ. Anticonvulsants for women with severe pre-eclampsia. In: Neilson JP, Crowther CA, Hodnett ED, Hofmeyr GJ, Keirse MJNC, eds. Pregnancy and childbirth module of the Cochrane Database of Systematic Reviews. [updated 3 June 1997]. The Cochrane Database of Systematic Reviews. [updated 3 June 1997]. The
Cochrane Library. Cochrane Collaboration; Issue 3. Oxford: Update SoftCochrane Library. Cochrane Coll
ware, 1997. Updated quarterly.

5 Douglas KA, Redman CWG. Eclampsia in the United Kingdom. BMJ 1994;309:1395-1400.

(Accepted 5 August 1997)

\title{
Satisfaction with clinical nurse specialists in a breast care clinic: questionnaire survey
}

Linda Garvican, Elisabeth Grimsey, Peter Littlejohns, Sue Lowndes, Nigel Sacks

Health Care Evaluation Unit, Department of Public Health Sciences,

St George's

Hospital Medical School, London SW17 0RE

Linda Garvican, senior research fellow Peter Littlejohns, director

continued over
Specialist nurses have an established role in the management of breast cancer in helping patients to understand their disease and treatment options, and in offering counselling and emotional support ${ }^{12}$; they are not usually involved in diagnosis.

In 1987 two clinical nurse specialists were appointed to the breast care clinic at our hospital; they were given responsibility for running outpatient clinics for symptomatic patients, including new referrals. The nurses take histories, examine the women, request imaging, and perform fine needle aspirations when appropriate. Test results are given by the nurses to both the patients and their general practitioners. The specialist surgeon sees patients who have been newly diagnosed with cancer and any patients for whom the evidence is equivocal. This paper describes patient satisfaction with a nurse led clinic screening for breast diseases in London and assesses the clinical expertise of the nurses.

\section{Subjects, methods, and results}

A specifically designed patient satisfaction questionnaire was distributed to 150 consecutive new referrals seen by the nurses during six weeks in June and July 1996. Altogether 119 questionnaires (79\%) were returned after a postal reminder.

Women were asked to rank their opinion of eight features of the clinic on a four point scale which ranged from very satisfied to very disappointed. Forty out of $118(34 \%)$ women were very satisfied with the amount of time it took to obtain an appointment. Altogether 47 out of $117(40 \%)$ women were very satisfied with the amount of time they spent waiting at the hospital, 39 out of $113(35 \%)$ were very satisfied with the facilities in the clinic, and 75 out of $113(66 \%)$ were very satisfied with the way the clinic was run. A total of 88 out of 117 $(75 \%)$ women rated themselves as very satisfied with the speed of diagnosis or reassurance, 67 out of 115 $(58 \%)$ were very satisfied with the amount of time taken 
Cytological results of fine needle aspirations for all breast lesions by clinician doing the aspiration and classification of sample. Values are number of aspirations done by each type of clinician (percentage; $95 \%$ confidence interval)

\begin{tabular}{|c|c|c|c|c|c|c|c|c|c|}
\hline \multirow[b]{2}{*}{ Classification } & \multicolumn{8}{|c|}{ Clinician doing aspiration } & \multirow[b]{2}{*}{ Total } \\
\hline & $\begin{array}{l}\text { Consultant } \\
\text { surgeon }\end{array}$ & Pathologist & Radiologist & $\begin{array}{c}\text { Senior } \\
\text { registrar* }\end{array}$ & Registrar* $^{*}$ & $\begin{array}{l}\text { Research } \\
\text { registrar* }\end{array}$ & $\begin{array}{c}\text { Clinical } \\
\text { assistant }\end{array}$ & $\begin{array}{c}\text { Clinical nurse } \\
\text { specialist }^{\star}\end{array}$ & \\
\hline $\begin{array}{l}\text { C1 (inadequate } \\
\text { sample) }\end{array}$ & $38(58 ; 46$ to 70$)$ & 0 & $6(11 ; 3$ to 19$)$ & $16(55 ; 37$ to 73$)$ & $39(41 ; 31$ to 51$)$ & $32(42 ; 31$ to 53$)$ & $31(24 ; 16$ to 31$)$ & $114(31 ; 27$ to 36$)$ & 276 \\
\hline C2 (benign) & $15(23)$ & $4(50)$ & $28(50)$ & $12(41)$ & $42(44)$ & $34(44)$ & $73(55)$ & $206(57)$ & 414 \\
\hline $\begin{array}{l}\text { C3 (probably } \\
\text { benign) }\end{array}$ & $2(3)$ & $1(13)$ & $4(7)$ & 0 & $6(6)$ & $1(1)$ & $9(7)$ & $5(1)$ & 28 \\
\hline $\begin{array}{r}\text { C4 (probably } \\
\text { malignant) }\end{array}$ & $2(3)$ & 0 & $8(14)$ & $1(3)$ & 0 & 0 & $4(3)$ & $11(3)$ & 26 \\
\hline C5 (malignant) & $9(14)$ & $3(38)$ & $10(18)$ & 0 & $8(8)$ & $10(13)$ & $15(11)$ & $26(7)$ & 81 \\
\hline $\begin{array}{l}\text { Total number of } \\
\text { aspirates }\end{array}$ & 66 & 8 & 56 & 29 & 95 & 77 & 132 & 362 & 825 \\
\hline $\begin{array}{l}\text { Ratio of benign: } \\
\text { malignant } \\
\text { samples }\end{array}$ & 0.6 & 1.3 & 2.8 & NA & 5.3 & 3.4 & 4.9 & 7.9 & 5.1 \\
\hline
\end{tabular}

$\mathrm{NA}=$ not applicable.

${ }^{*}$ Combined results of two clinicians at each grade.

for consultation, and 83 out of $118(70 \%)$ were very satisfied with the standard of care provided. Twenty six of 93 women $(28 \%)$ were very satisfied with car parking, public transportation, or other access to the hospital.

Only five women had expected to see a nurse. All women were satisfied or very satisfied with the clinical care they received, and 19 out of $118(16 \%)$ added specific praise to their questionnaires. Evaluation of clinical care and hospital services overall showed that the women were significantly more satisfied with the nurses $\left(\chi^{2}\right.$ with Yates's correction $=22.5,1 \mathrm{df}$, $\mathrm{P}<0.0001)$ than with other aspects of hospital care.

A postal questionnaire was sent to each woman's general practitioner; 102 out of $150(68 \%)$ questionnaires were returned. Altogether 99 questionnaires were analysed. Sixty four out of $91(70 \%)$ of general practitioners always or regularly referring patients to the clinic were aware of the nurses' role but only 8 out of $91(9 \%)$ had informed their patients that the clinic was run by nurses. The most common reasons for referral to the clinic were the high standard of care and convenient location; however, some referrals were the result of a request by the patient to attend our clinic. There were no complaints about patients being misdiagnosed.

To measure the nurses' technical expertise the results of fine needle aspirations of breast lesions were audited by type of clinician who did the aspiration and classification of disease. Pathologists had the lowest percentage of inadequate samples; their samples tended to be from gross lesions detected by other team members, as indicated by the high proportion of malignancies identified (table). A lower percentage of inadequate samples were aspirated by the specialist nurses compared with other team members across the range presenting symptoms.

\section{Comment}

Both patients and purchasers of health care expect patients referred for outpatient care to be seen by specialists. Historically this has meant patients were seen by consultants. Clinical guidelines on the management of symptomatic breast disease ${ }^{3}$ require that referrals occur rapidly. According to the same guidelines, breast care clinics should treat 100 to 150 new cases of cancer annually; this is equivalent to 1000 to 1500 new referrals. A single consultant cannot see this many patients in an outpatient clinic. Our study suggests that clinical nurse specialists can provide outpatient care in the absence of a second consultant.

In this study, being seen by specialist nurses was acceptable to patients and general practitioners; the nurses' clinical expertise compared favourably with that of other clinicians. Other studies have found that pathologists may be less likely to classify their own samples as inadequate ${ }^{4}$ but it seems that variations in the rate of inadequate samples partially reflect the skill of the clinician doing the aspiration.

In another study patients were randomly allocated to be seen either by a nurse practitioner or a junior doctor. ${ }^{5}$ Patients who saw the nurse practitioner expressed more satisfaction and had less anxiety than those who saw either male or female junior doctors. No difference was found in adherence to protocols between the nurse practitioners and the junior doctors. Further trials are required to determine whether any cost-benefit results from nurse led clinics.

We thank Dr Janet Peacock for statistical advice.

Contributors: NS initiated the study. The study was planned by LG and PL. LG designed the questionnaires, analysed the data, interpreted the results, and is guarantor for the study. EG and SL distributed questionnaires and conducted the cytology audit. The paper was written by LG, PL, and NS.

Funding: The Health Care Evaluation Unit is funded by the Research and Development Directorate of the NHS Executive South Thames.

Conflict of interest: None.

1 English T. Medicine in the 1990s needs a team approach. $B M J$ 1997;314:661-3.

2 Watson M, Denton S, Baum M, Greer S. Counselling breast cancer patients: a specialist nurse service. Counselling Psychiatry Q 1988;1:25-34.

3 Breast Surgeons Group of the British Association of Surgical Oncology. Guidelines for surgeons in the management of symptomatic breas disease in the United Kingdom. Eur J Surg Oncol 1995;21(suppl):1-13A.

4 Brown LA, Coghill SB, Powis SJA. Audit of diagnostic accuracy of FNA cytology specimens taken by the histopathologist in a symptomatic breast clinic. Cytopathology 1991;2:1-6.

5 Hammond C. A nurse practitioner-doctor comparison study at the Nige Porter breast care unit at the Royal Sussex County Hospital, Brighton [dissertation]. University of Surrey, 1994.

(Accepted 31 October 1997)
Breast Unit, St George's Hospital, London SW17 0QT Elisabeth Grimsey, clinical nurse specialist Sue Lowndes, clinical nurse specialist Nigel Sacks, consultant surgeon

Correspondence to: Dr Garvican linda.garvican@ btinternet.com 